\title{
Patient-centred perioperative mobile application in Cesarean delivery: needs assessment and development
}

\section{Évaluation des besoins et mise au point d'une application mobile périopératoire centrée sur la patiente accouchant par césarienne}

\author{
Janny Xue Chen Ke, MD (1) - Ronald B. George, MD, FRCPC • Lori Wozney, PhD • \\ Jill L. Chorney, PhD
}

Received: 29 November 2018/Revised: 16 February 2019/Accepted: 23 March 2019/Published online: 13 May 2019

(C) Canadian Anesthesiologists' Society 2019

\begin{abstract}
Purpose Cesarean delivery $(C D)$ is the most commonly performed inpatient surgery in Canada, with 103,425 performed in 2016-2017. Mobile technology can contribute to patient-centred perioperative care. Our aim was to involve patients and anesthesiologists in designing a mobile application to enhance the perioperative care of CD patients.

Method We completed an exploratory qualitative study involving three iterative design cycles. Individual structured phone or in-person interviews with $C D$ patients $(n=15)$ and anesthesiologists $(n=9)$ were conducted. Thematic analysis was used to 1) assess gaps and opportunities in the anesthesiology care after $C D, 2$ ) identify roles and limitations of mobile application technology in bridging perioperative care, and 3) to solicit feedback on a prototype mobile application for the anesthesiology postoperative care of elective CD patients.
\end{abstract}

Electronic supplementary material The online version of this article (https://doi.org/10.1007/s12630-019-01392-x) contains supplementary material, which is available to authorized users.

J. X. C. Ke, MD ( $ه)$

Department of Anesthesiology, Pain Management, and Perioperative Medicine, Dalhousie University, Halifax, NS, Canada

e-mail: jannyke@dal.ca

R. B. George, MD, FRCPC · J. L. Chorney, PhD Department of Anesthesiology, Pain Management, and Perioperative Medicine, Dalhousie University, Halifax, NS, Canada

IWK Health Centre, Halifax, NS, Canada

L. Wozney, PhD

IWK Health Centre, Halifax, NS, Canada
Results Patients and anesthesiologists were in favour of adding mobile applications to the interdisciplinary perioperative management of patients undergoing $C D$, particularly for providing reliable information, identifying and following patients with complications, and research in perioperative outcomes. Medical-legal issues, privacy, workflow, and payment policy frameworks are barriers for mobile technology linking patients and anesthesiologists. Our final prototype was refined to focus on timely, concise education and self-monitoring.

Conclusion The participant-driven changes in direction of the prototype showed the importance of involving key stakeholders early. This study provides guidance on further iterative development and implementation of an interdisciplinary mobile platform for patient-centred perioperative care and outcomes research.

\section{Résumé}

Objectif L'accouchement par césarienne est la chirurgie avec hospitalisation la plus fréquemment réalisée au Canada, atteignant 103425 cas en 2016-2017. La technologie mobile pourrait contribuer aux soins périopératoires centrés sur la patiente. Notre objectif était d'impliquer les patientes et les anesthésiologistes pour mettre au point une application mobile afin d'améliorer les soins périopératoires des femmes accouchant par césarienne.

Méthode Nous avons réalisé une étude qualitative exploratoire comprenant trois cycles itératifs de conception. Des entretiens individuels structurés par téléphone ou en personne avec des patientes subissant une césarienne $(n=15)$ et des anesthésiologistes $(n=9)$ ont été menés. Une analyse thématique a été utilisée pour 1) évaluer les écueils et les opportunités dans les soins anesthésiques après une césarienne, 2) identifier les rôles 
et les limites de la technologie d'application mobile pour combler les besoins des soins périopératoires, et 3) demander une rétroaction concernant un prototype d'application mobile pour les soins anesthésiques postopératoires des patientes subissant une césarienne planifiée.

Résultats Les patientes et les anesthésiologistes étaient en faveur de l'ajout d'applications mobiles à la prise en charge périopératoire des patientes subissant une césarienne, particulièrement pour offrir des informations fiables, identifier et faire le suivi des patientes souffrant de complications, et effectuer de la recherche sur les pronostics périopératoires. Les questions médicolégales, le respect de la vie privée, la charge de travail et les cadres de politiques de paiement constituent des obstacles à la connexion des patientes et des anesthésiologistes via la technologie mobile. Notre prototype final a été amélioré afin de se concentrer sur des outils de formation concis et opportuns et sur l'auto-monitorage.

Conclusion Les changements proposés au prototype par les participants ont démontré l'importance d'impliquer les principaux intéressés tôt dans le processus. Cette étude offre des pistes quant à la mise au point et la mise en ouvre progressives d'une plateforme mobile interdisciplinaire pour des soins périopératoires centrées sur les patients et la recherche sur les pronostics périopératoires.

Cesarean delivery (CD) is the most commonly performed inpatient surgery in Canada, with 103,425 performed in

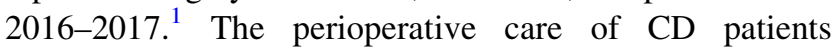
encompasses rural and urban settings and multiple health professions. Obstetric complications related to CD include infection, bleeding, injury to surrounding structures, and nerve injury. ${ }^{2}$ Anesthetic issues include pain management, post-dural puncture headache, neurologic injury, and chronic pain. $^{2-4}$ The average length of stay after $\mathrm{CD}$ is 3.1 days, ${ }^{1}$ indicating that most of the recovery occurs in the outpatient setting. Continuity of care is crucial in ensuring optimal preoperative preparation, monitoring of rare postoperative complications, and providing patient education.

Nevertheless, obstetric anesthesiologists have few existing mechanisms for routine monitoring of potential anesthesiology-related complications. With increasing emphasis on patient-centred care, mobile technology may provide an accessible, versatile platform for perioperative care and research. ${ }^{5,6}$ Mobile phone ownership is prevalent, reaching $82 \%$ of Canadians in $2017 .{ }^{7}$ More than $80 \%$ of the time spent on smartphones was on mobile applications. ${ }^{7}$ Of adults aged 18-29 years and 30-49 years, 94\% and 89\% own smartphones, respectively. ${ }^{8}$ Nevertheless, while a few postoperative mobile applications exist, our understanding of patient and anesthesiologist needs and opportunities in perioperative care remain limited. ${ }^{5,9-11}$ A review of anesthesiology mobile applications revealed more than 300 applications, the majority of which are clinical references for anesthesiologists, but none are for perioperative patient care and education. ${ }^{12}$

Our aim was to involve patients and anesthesiologists in designing a mobile application to enhance the perioperative care of elective CD patients. Through interviews, this study sought to explore the needs of patients and anesthesiologists regarding postoperative follow-up, as well as the benefits and caveats for mobile application to facilitate perioperative care. Based on interview findings, a patient-centred mobile application was developed through an iterative process.

\section{Methods}

Our study was approved by the institutional Research Ethics Board (REB\# 1020938) and was performed at IWK Health Centre, a tertiary academic hospital for women and children in Halifax, Nova Scotia. Written informed consent was obtained from all participants. The inclusion criteria for obstetric anesthesiologists were: a practicing core obstetric anesthesiologist at the IWK Health Centre, selfreported possession and regular use of a smartphone, and self-reported proficiency with mobile communication devices and mobile applications (defined as use of smartphone more than five times per day for email, texting, or other non-calling phone features). There were no exclusion criteria for anesthesiologists.

The inclusion criteria for patients were: elective $C D$, non-labouring at recruitment, term gestation (37-42 weeks), normal fetus, American Society of Anesthesiologists' physical status II-III, availability within four weeks postpartum for the interview, ability to participate in-person or via teleconference, possesses a smartphone and uses it on a regular basis, self-reported proficiency with smartphone and mobile applications (same as those for anesthesiologists), and reported fluency in English. The exclusion criteria were any selfreported physical or psychiatric condition that might impair the ability to participate in the interview process or provide insights representative of the general population.

The primary aim of the study was to develop a mobile application prototype for the anesthesiology postoperative care of elective CD patients. To achieve this, we had to identify the gaps and opportunities in anesthesiology care after $\mathrm{CD}$ and explore the roles and limitations of mobile applications in the postoperative care environment. Three 
cycles of individual interviews for anesthesiologists and patients were conducted. Each cycle was led by a different study team member and involved different participants.

Offered in-person or by phone, the interviews were audiotaped and fully transcribed for subsequent analysis. Patients were interviewed within four weeks postpartum to allow for time to reflect about their postoperative experience. Following initial data gathering, participants were then able to interact with the prototype (built with Balsamiq $^{\mathrm{TM}}$ or an equivalent interactive PDF in cycles 1 and 2, and CanvasFlip ${ }^{\mathrm{TM}}$ for cycle 3), and give feedback focusing on appearance, content, navigation, and overall user experience. Each participant received a \$20 gift card honorarium. At the end of each cycle, the interview transcripts were analyzed to identify themes pertaining to the primary study objectives. In addition, study investigators debriefed the participants to identify 1) essential improvements for the prototype and 2) refocusing of interview questions for the next cycle.

\section{Sample size}

Mathematical modelling by Nielsen and Landauer ${ }^{13}$ found that five users allows for the discovery of $85 \%$ of usability problems. Based on this, the sample size consisted of 15 patients (average five per cycle) and nine anesthesiologists (three per cycle). The total number of core obstetric anesthesiologists at our institution is ten, which gave us an anesthesiology sample size of nine after excluding our study team member (R.G.). Three iterative cycles would provide a reasonable prototype, which was recommended by mobile application industry experts ${ }^{14}$ and trialed in a mobile application design study for patients in the primary care setting. ${ }^{15}$

\section{Results}

Recruitment and data collection were completed between May 2016 and June 2017. We approached 25 eligible patients and obtained informed consent from 21, of which six were lost to follow-up prior to interviews. Fifteen patients participated (four for cycle 1, six for cycle 2, and five for cycle 3). Nine obstetric anesthesiologists participated (three per cycle). Demographics are summarized in Tables 1 and 2. Mean (standard deviation) duration for interviews were 51 (4), 45 (11), and 12 (4) minutes for cycles 1,2 , and 3 , respectively.

The iterative development process

A summary of the design process is shown in Fig. 1. In cycle 1, participants reviewed a mock-up of a mobile application that tracks important symptoms and facilitates interaction between patients and anesthesiologists (available as ESM eFig. 1). Based on feedback, additional features (e.g. decision tree) and functionality were added to the simple mock-up of the app (ESM eFig. 2). In cycle 2, anesthesiologists raised concerns about the safety of a decision tree and a team decision was made to pivot the design and build an application for patients only. While results from cycles 1 and 2 continued to inform our design decisions, cycle 3 focused on patient education and self-monitoring and contained specific education topics that were featured before and after surgery (ESM eFig. 3). On days 1-3 and day 5 after surgery, self-check reminders would appear, leading to relevant resources if symptoms were chosen. We simulated real-time daily notifications by texting patients the website to the interactive mobile prototype. After cycle 3, we completed a final round of design modifications and hired a company to build a free iOS mobile application called C-Care $\bigodot^{16}$ (Figs 2-6) that will be evaluated in a future study.

Development of and feedback from cycles 1-2

\section{PATIENTS}

In cycles 1 and $2(n=10)$, patients identified that the perioperative mobile application could be useful in facilitating a reliable source of information $(n=6)$, safety $(n=6)$, direct link and communication with a health professional $(n=6)$, reassurance $(n=4)$, tracking and recording recovery $(n=3)$, and research $(n=2)$. In terms of being a reliable source of information, one patient commented, "I was up every night Googling random stuff about C-sections.... [It] would have been nice to go somewhere specific where you can download an app and get all the information that you need." Another patient said the information would provide reassurance: "And they say every time you have a child, you're like a first-time mother all over again. You know, there's something sort of isolating about the experience. And I feel like an app like this could provide some peace of mind that I think women really need when they're going through this process." One patient wished she was educated more about signs to monitor for after a spinal. Another would have liked to learn more about the process of recovery. Interestingly, six patients already used mobile applications to track healthrelated data.

Potential barriers to a perioperative mobile application include confidentiality and privacy $(n=6)$, lack of patient buy-in $(n=4)$, lack of resources $(n=4)$, lack of doctor buyin $(n=2)$, medical-legal concerns $(n=2)$, and lack of prompts to interact with the application $(n=2)$. Less frequently mentioned concerns included technical issues, 
Table 1 Demographics of patients

\begin{tabular}{|c|c|c|}
\hline \multicolumn{2}{|l|}{ Category } & \multirow{2}{*}{$\frac{n}{34(4) \mathrm{yr}}$} \\
\hline Age $(\mathrm{yr})$, mean $(\mathrm{SD}))$ & & \\
\hline \multirow[t]{4}{*}{ Highest level of education obtained } & Community college diploma & 4 \\
\hline & University degree & 5 \\
\hline & Masters/PhD & 3 \\
\hline & Second university degree (e.g. Law, MD, MBA...) & 3 \\
\hline \multirow[t]{3}{*}{ Ethnic category } & Caucasian & 10 \\
\hline & African Canadian & 3 \\
\hline & Arab & 2 \\
\hline \multirow[t]{2}{*}{ Current relationship status } & Married & 12 \\
\hline & Living with a partner & 3 \\
\hline \multirow[t]{5}{*}{ Household income before taxes } & $39-62,000$ & 3 \\
\hline & $62-88,000$ & 3 \\
\hline & $>88-125$ & 4 \\
\hline & $>125,000$ & 3 \\
\hline & I don't wish to answer & 2 \\
\hline \multirow{2}{*}{\multicolumn{2}{|c|}{ Number of previous pregnancies }} & Median 2 \\
\hline & & Range, $1-5$ \\
\hline \multirow{2}{*}{\multicolumn{2}{|c|}{ Number of previous deliveries }} & Median 1 \\
\hline & & Range, $1-3$ \\
\hline \multirow{2}{*}{\multicolumn{2}{|c|}{ Number of previous deliveries that were by Cesarean delivery }} & Median 1 \\
\hline & & Range, $1-3$ \\
\hline
\end{tabular}

$\mathrm{SD}=$ standard deviation

Table 2 Demographics of anesthesiologists

\begin{tabular}{lll}
\hline Category & & $n$ (out of 9) \\
\hline Age $(\mathrm{yr})$ & $>30-40$ & $2(22 \%)$ \\
& $>40-50$ & $4(44 \%)$ \\
& $>50-60$ & $3(33 \%)$ \\
Years in practice & $<5$ & $2(22 \%)$ \\
& $5-10$ & $1(11 \%)$ \\
& $>10-20$ & $6(67 \%)$ \\
\hline
\end{tabular}

capacity of understanding, serious complication precluding interaction with the application, not having any complications, and health team human resources.

\section{Obstetric anesthesiology staff}

Opportunities identified by anesthesiologists are similar to those identified by the patients, including research and quality improvement $(n=3)$, a record of signs and symptoms $(n=2)$, ease of follow-up $(n=2)$, follow-up of specific patients $(n=2)$, expedited recovery programs $(n$ $=1)$, and patient education $(n=1)$. One anesthesiologist emphasized the importance of postoperative follow-up to identify complications and audit one's own practice. Another anesthesiologist commented on the feasibility of workflow: "If you've had a shift with seven sections and you had seven groups of data sets coming back to you, obviously it's going to be a little more information. But on the average day, it wouldn't be difficult at all to open this app and just look at the... I assume it's going to be their pain scores, nausea scores, itch scores and other complications. And you could quickly look at that and see if the patient did today were, you know, high rankings and figure out why that was.... It seems like it would be a very easy thing to maneuver time-wise."

Moreover, the application could facilitate patient education: "Patients don't always know or understand everything you say to them in a preoperative clinic setting or they don't have time to process it. So if there's some availability for questions that come up in their mind before they come to the operating room, it might help with that. And understanding both preop[erative] and intraop[erative] and postop[erative] courses.... what we expect from them in terms of managing their medications and their medical conditions." Similar to patients, anesthesiologists suggested the application could be used to follow highrisk patients: "I don't know if I would use it for every single patient. I would be interested in using it for patients whom, in my opinion, had some sort of an adverse event, some sort of a complication, something unexpected 


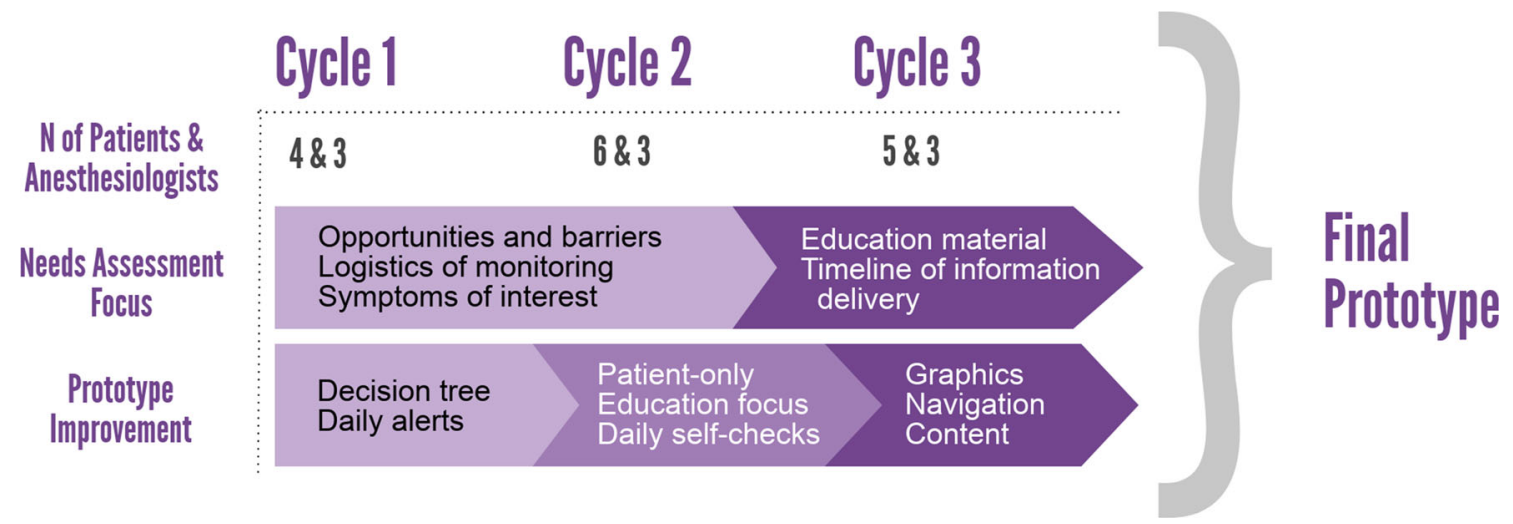

Fig. 1 Flowchart summary of the development process

happen. Somebody that I wanted to follow up for a particular reason."

Nevertheless, anesthesiology participants pointed out that there is insufficient regulation to address potential medical-legal $(n=5)$ and privacy $(n=4)$ issues for an application that involves direct physician-patient interaction, and raised several concerns as follows. Communication and documentation within the application could be taken out of context. Medical decisions could be made without physical exam or access to full patient information. One anesthesiologist raised, "Who has access to the responses that I provide? Because if a patient receives information from me which they hold onto and is taken out of context, in a medical-legal situation, then that's a big issue as well." Others are concerned about the use of a decision tree algorithm, pointing out that the red flags need to be correctly identified among routine information and the application should not be used for emergencies.

In addition, staffing issues would be a significant barrier ( $n=4)$, with several themes identified as follows. Anesthesiologists questioned who is ultimately responsible for the patient via the application, such as who should be answering preoperative questions when there is a variation in practice, handover challenges after hours, and interdisciplinary communication and referral. If there is a high volume of patient information, notifications could be disruptive for a normal work day. There is also a fear of being woken up at night for non-emergent issues. Documentation would need to be streamlined to avoid the duplicate work of documenting both within the application and in the patient's chart. Not all anesthesiologists would have the technologic skills or hardware access to use the application. Group buy-in would be required, otherwise patients may be dissatisfied in physicians not participating in the mobile service. One anesthesiologist commented, "So I mean this is interesting stuff, but I think this is more of a quality assurance thing than real-time patient management thing. I would hate to manage patients through an app. I'd rather have them come in and for me to talk to them." Thus, a clear framework for human resources, payment, and medical-legal protection would need to be established before using this application for direct patient care. Based on these anesthesiologists' concerns involving direct physician-patient contact, we pivoted to focus on making an application for patient education and self-monitoring. Highlights of the opportunities and barriers identified in cycles 1-2 are shown in Fig. 7.

\section{Logistics of monitoring}

We also asked all participants to identify signs and symptoms related to anesthesia that were most important for them to monitor postoperatively. The full list of issues was similar amongst patients and anesthesiologists: pain and pain medication use, nausea and vomiting, side effect of spinal anesthesia, numbness and weakness, bleeding, itching, incision issues, sleep, mobility, bowel movement, breastfeeding, and overall experience. Patients also reported the desire to track pregnancy-related issues such as gestational diabetes and preeclampsia. Patients reported willingness to enter routine data for monitoring purposes ranging from more than once a day $(5 / 10)$, daily $(4 / 10)$, to every few days (1/10), with a duration of a few days to a few months.

Patient responses for expectation of anesthesia followup after routine and uncomplicated surgery varied widely, ranging from none (3/10), day of surgery $(2 / 10)$, postoperative day one (2/10), a few days to one week (1/ $10)$, postoperative day one and in a few days (1/10), and one week (1/10). Perioperative follow-up by anesthesiologists is the ideal but is not routinely done in practice unless there is a complication. Anesthesiologists' 

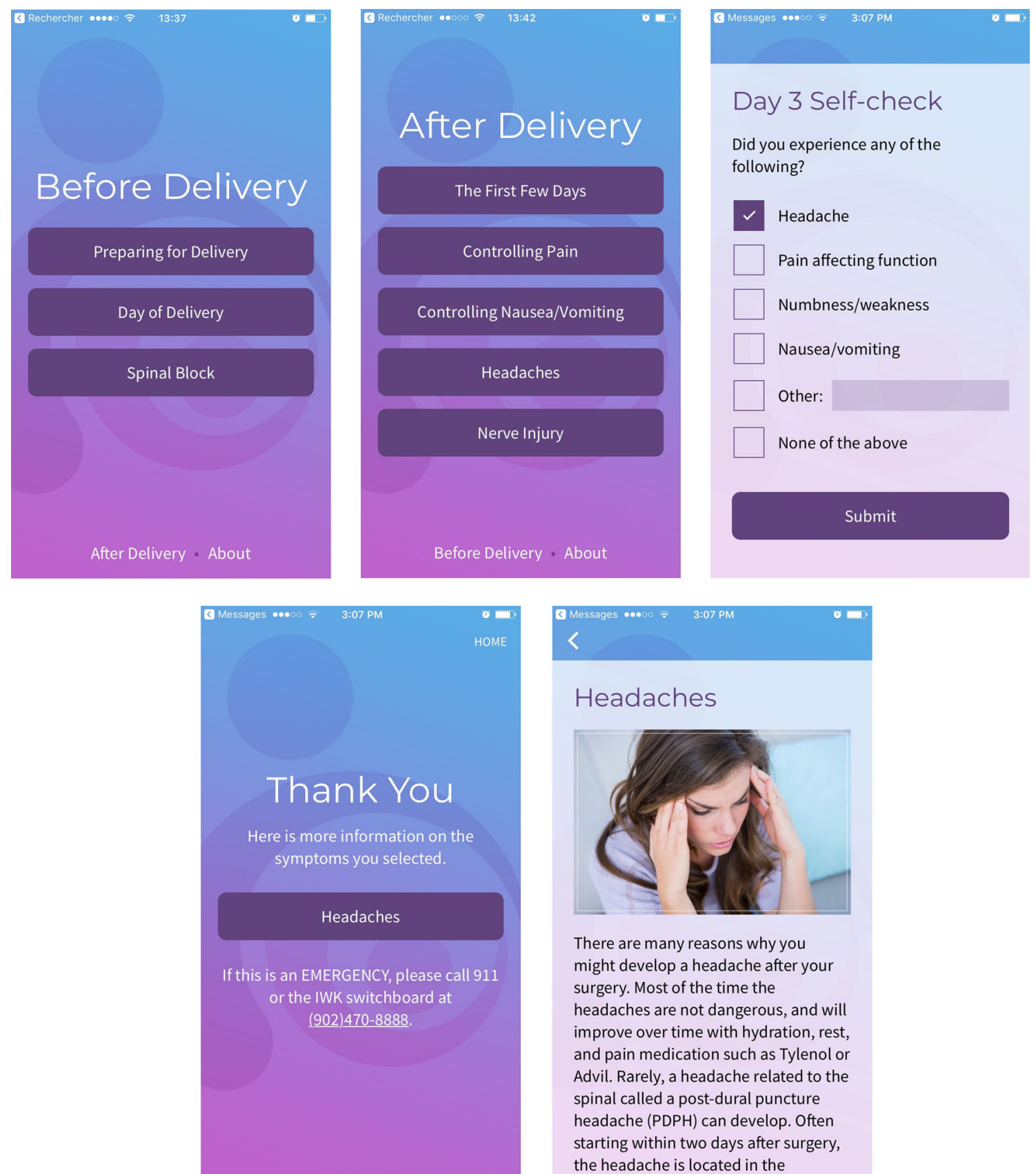

There are many reasons why you might develop a headache after your surgery. Most of the time the headaches are not dangerous, and will improve over time with hydration, rest, and pain medication such as Tylenol or Advil. Rarely, a headache related to the spinal called a post-dural puncture headache (PDPH) can develop. Often starting within two days after surgery, the headache is located in the

Figs 2-6 Selected screenshots from the final prototype as part of the C-Care $\subset$ mobile application

responses for the maximum duration of follow-up for routine cases ranged from one day (2/6), two days $(2 / 6)$, three days (1/6), and before discharge (1/6). Anesthesiologists identified several complications that would warrant a longer follow-up, which included neuraxial problems, failed block, problems with pain, complications (cardiac, respiratory, neurologic), unexpected events or side effects, intensive care admission, and massive transfusion.
Development of and feedback from cycle 3

Since we have reached saturation in terms of the interview responses in cycles $1-2$, in cycle 3 , we focused interview questions on the timing of patient education needs and consulted patients and anesthesiologists on a perioperative education and self-check timeline. Our real-time prototype testing in cycle 3 revealed that within five days postoperatively, four out of five patients interacted with the prototype at least twice, and two patients interacted with the prototype more than four times. The most 

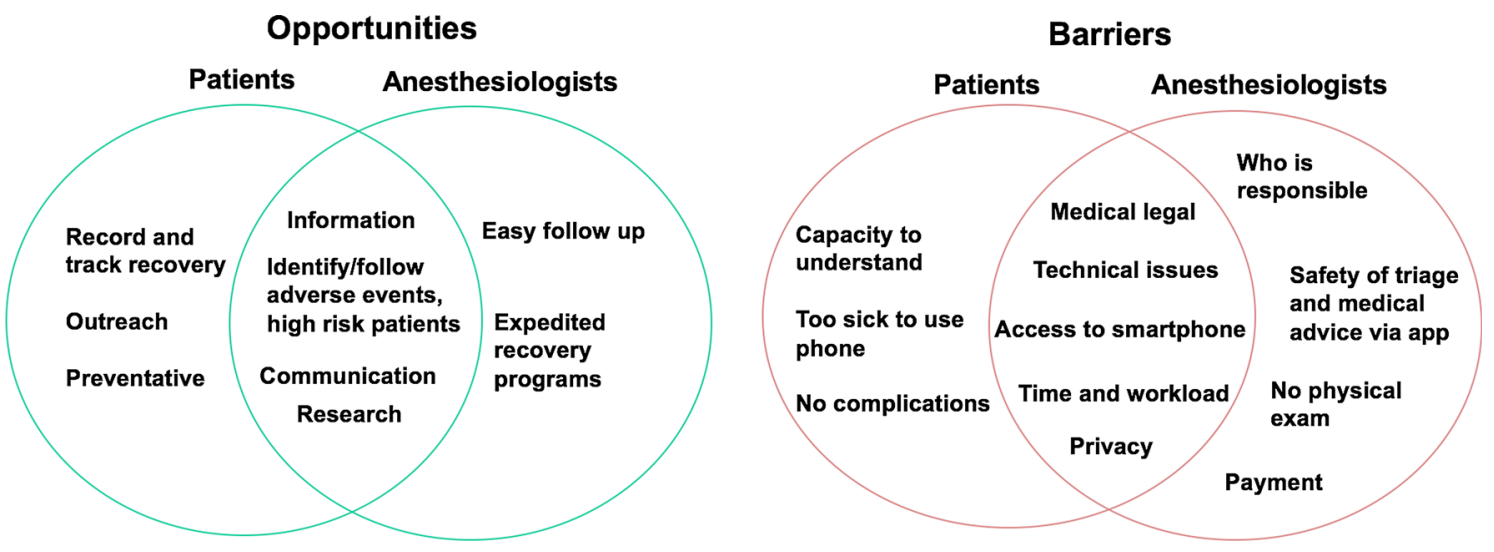

Fig. 7 Opportunities and barriers of a perioperative mobile application, from cycles 1-2 needs assessment

accessed resources were controlling pain, overview about days after surgery, and key contacts. Overall, patients gave excellent feedback for both the timeline and real-time user testing. Anesthesiologists emphasized that the application needs to be customizable, such as surgery date, complications, and information. Patients found the application was overall useful, straightforward, and accessible.

\section{Discussion}

Our study explored the addition of mobile applications in the perioperative care of $\mathrm{CD}$ patients and designed a prototype based on iterative feedback cycles. Patients were willing to engage with mobile postoperative monitoring, as shown from interviews and real-time testing. There is a need for mobile applications in the interdisciplinary perioperative management of patients undergoing $\mathrm{CD}$, particularly to provide reliable sources of information, identify and follow patients with complications, and conduct longitudinal research in perioperative outcomes. Other novel perioperative supports being explored in the literature are mobile-device-based monitoring (e.g. oxygen saturation and glucose), mobile personal health record, and image-based postoperative follow-up in wound care. ${ }^{5}$ While previous research also identified concerns about privacy, security, regulation, and sustaining patient engagement, ${ }^{6}$ this study revealed additional barriers such as staffing and medical-legal protection that need to be addressed.

In addition, our study highlights the importance of engaging end-users and key stakeholders early in the process of innovation and design. Our initial plan was to develop a telemonitoring system that would support data input from CD patients, as well as data visualization, analysis, and management decisions, similar to other postoperative monitoring mobile applications. ${ }^{5,9}$ Nevertheless, because of anesthesiology concerns over the lack of a medical-legal, privacy, workflow, and payment framework, we shifted our prototype to remove direct interaction among physicians and patients. Our final prototype targets patient-identified needs, focusing on timely, concise education and self-monitoring. In contrast to our co-design approach, a scoping review of mobile applications for pain self-management after surgery found that within the ten available applications, only five included a healthcare provider during development, and none included end-users. ${ }^{10}$ Also, none featured comprehensive content nor went through scientific evaluation. ${ }^{10}$ The iterative methodology of this study shows a participant-driven method to developing patientcentred, physician-vetted mobile interventions.

The strengths of our study include in-depth individual interviews that provided rich perspectives, and the iterative study design that allowed us to adapt to the results of the previous cycle and rapidly improve for the next cycle. In terms of limitations, while we met the recommended number of testers for identifying major usability problems, the generalizability of our results is confined by the small sample size and tertiary hospital setting.

In the fragmented market of mobile applications, a standardized perioperative platform with interoperability between devices and health records would be key to generalizability. ${ }^{6}$ Future research should also include multicentre, multidisciplinary development and implementation in a larger and more diverse sample of patients and surgeries. Furthermore, the mobile application could serve as a platform for perioperative patient-oriented outcomes research. Based on results from this iterative research, a cohort study evaluating patient engagement with the mobile application after CD is underway (NCT\# 03746678). In the future, we hope to expand the use of mobile application into other anesthesia care areas and 
study its usability and implementation at a population level.

In conclusion, mobile technology may play a key role in enhancing the postoperative anesthesia care of elective CD patients. Participants pinpoint patient education, early identification and follow-up of complications, and research as key opportunities, and human resources and lack of medical-legal protection as important barriers. The many participant-driven changes in direction in the prototype showed the importance of involving key stakeholders early in the design process. This study provides guidance for further iterative development and implementation of a mobile monitoring and communication platforms for patient-centred perioperative care and research. Nevertheless, policy frameworks need to be established in Canada before wide scale adoption of mobile health technology connecting patients and physicians.

Acknowledgements We would like to thank our exceptional research staff including Lorraine Chiasson, Robin Lake, Kimberly Vella, and Brianne Lindsay. We are also grateful for funding from the Dalhousie University Department of Anesthesia, Pain Management, and Perioperative Medicine. We thank Optio Publishing Inc. for working with us to build the mobile application.

Conflicts of interest None declared.

Editorial responsibility This submission was handled by Dr. Philip M. Jones, Associate Editor, Canadian Journal of Anesthesia.

Author contributions Janny Xue Chen Ke, Ronald B. George, Lori Wozney, and Jill L. Chorney contributed to all aspects of this manuscript, including study conception and design, analysis and interpretation of data, and drafting the article.

Disclosures This work was funded by the Department of Anesthesiology, Pain Management, and Perioperative Medicine, Dalhousie University.

\section{References}

1. Canadian Institute for Health Information. Inpatient Hospitalizations, Surgeries, Newborns and Childbirth Indicators in 2015-2016. Available from URL: https://secure.cihi.ca/estore/ productFamily.htm?pf=PFC3424\&lang=en\&media=0 (accessed March 2019).
2. Chestnut DH, Wong CA, Tsen LC, Ngan Kee WD, Beilin Y, Myhre $J$. Chestnut's Obstetric Anesthesia: Principles and Practice, 5th ed. Elsevier; 2014.

3. Jin J, Peng L, Chen $Q$, et al. Prevalence and risk factors for chronic pain following cesarean section: a prospective study. BMC Anesthesiol 2016; 16: 99.

4. Kainu JP, Halmesmäki E, Korttila KT, Sarvela PJ. Persistent pain after cesarean delivery and vaginal delivery: a prospective cohort study. Anesth Analg 2016; 123: 1535-45.

5. Simpao AF, Lingappan AM, Ahumada LM, Rehman MA, Gálvez $J A$. Perioperative smartphone apps and devices for patientcentered care. J Med Syst 2015; 39: 102.

6. Rothman BS, Gupta RK, McEvoy MD. Mobile technology in the perioperative arena: rapid evolution and future disruption. Anesth Analg 2017; 124: 807-18.

7. Segal B. Global Digital Future in Focus 2018 Canada Edition. Available from URL: http://www.comscore.com/Insights/ Presentations-and-Whitepapers/2018/Global-Digital-Future-inFocus-2018-Canada-Edition (accessed March 2019).

8. Pew Research Center. Mobile Fact Sheet. Available from URL: http://www.pewinternet.org/fact-sheet/mobile/ (accessed March 2019)

9. Lu K, Marino NE, Russell D, et al. Use of short message service and smartphone applications in the management of surgical patients: a systematic review. Telemed J E Health 2018; 24: 40614.

10. Lalloo $C$, Shah $U$, Birnie $K A$, et al. Commercially available smartphone apps to support postoperative pain self-management: scoping review. JMIR Mhealth Uhealth 2017; 5: e162.

11. Kraidin J, Ginsberg SH, Solina A. Anesthesia apps: overview of current technology and intelligent search techniques. J Cardiothorac Vasc Anesth 2012; 26: 322-6.

12. Green MS, Mathew JJ, Gundigi Venkatesh A, Green P, Tariq R. Utilization of smartphone applications by anesthesia providers. Anesthesiol Res Pract 2018; 2018: 8694357.

13. Nielsen J, Landauer TK. A mathematical model of the finding of usability problems. In: Proceedings of the INTERACT ' 93 and CHI '93 Conference on Human Factors in Computing Systems. NY, USA: ACM; 1993: 206-13. Available from URL: http://doi. acm.org/10.1145/169059.169166 (accessed March 2019).

14. Nielsen Norman Group. Why You Only Need to Test with 5 Users. Available from URL: https://www.nngroup.com/articles/ why-you-only-need-to-test-with-5-users/ (accessed March 2019).

15. Steele Gray $C$, Khan AI, Kuluski K, et al. Improving patient experience and primary care quality for patients with complex chronic disease using the electronic patient-reported outcomes tool: adopting qualitative methods into a user-centered design approach. JMIR Res Protoc 2016; 5: e28.

16. C-Care. App Store. Available from URL: https://itunes.apple. $\mathrm{com} / \mathrm{ca} / \mathrm{app} / \mathrm{c}$-care/id1373322196? mt=8 (accessed March 2019).

Publisher's Note Springer Nature remains neutral with regard to jurisdictional claims in published maps and institutional affiliations. 